\title{
RECURSOS HÍDRICOS EM MUNICIPIOS CATARINENSES E O TRABALHO DA ESCOLA
}

\author{
WATER RESOURCES IN CATARINENSE TOWNS AND THE \\ SCHOOL WORK \\ RECURSOS HÍDRICOS EN MUNICIPIOS CATARINENSES Y EL \\ TRABAJO DE LA ESCUELA
}

\author{
Sandra Luciana Dalmagro \\ https://orcid.org/oooo-0oo1-9639-7070 \\ Janaina Goulart Oliveira de Queiroz \\ (iD) https://orcid.org/oooo-0oo2-4057-2535
}

\begin{abstract}
REVISTA PEDAGÓGICA
Revista do Programa de Pós-graduação em Educação da Unochapecó | ISSN 1984-1566

Universidade Comunitária da Região de Chapecó | Chapecó-SC, Brasil Como referenciar este artigo: DALMAGRO, S. L.; QUEIROZ, J. G. O. Recursos hídricos em municípios catarinenses e o trabalho da escola. Revista Pedagógica, Chapecó, v. 22, p. 1-17, 2020. DOI: http://dx.doi.org/10.22196/rp.v22io.4570
\end{abstract}

\section{OBS: A pesquisa teve financiamento do FNDE.}

Resumo: O artigo apresenta resultados de pesquisa desenvolvida no âmbito do Programa de Educação Tutorial/Educação do Campo/UFSC acerca da problemática com os recursos hídricos em municípios catarinenses e o trabalho de escolas com esta temática. Os municípios investigados são Urubici, Três Barras e Passos Maia, nos quais, respectivamente, são abordados o uso de agrotóxicos, a indústria do papel e as Pequenas Centrais Hidrelétricas. Foram realizadas entrevistas com estudantes, docentes e moradores, e observações nas escolas, nos rios, fontes de água, lavouras e indústrias em questão. As conclusões apontam problemas de poluição, contaminação e apropriação privada dos cursos de água, sua íntima articulação com os setores prioritários da economia catarinense e com a forma de produção que visa o lucro e degrada o meio ambiente. Quanto ao trabalho escolar, identificamos que o tema água é abordado em todas as escolas, porém de forma descontextualizada dos problemas concretos, restrito à esfera do consumo e da responsabilização individual.

Palavras-chave: Recursos Hídricos. Economia catarinense. Escola. Educação do Campo.

Abstract: The article presents research results developed in the PET/Field Education/UFSC sphere regarding the water resources issue in Catarinense towns and the school work around this theme. The investigated towns are Urubici, Três Barras and Passos Maia, in which, respectively, the use of pesticides, the paper industry and the PCHs are approched. Students, teachers and inhabitants were interviewed as well as rivers, water sources, plantations and the focused industries were monitored. The conclusions indicate pollution problems, contamination and private appropriation of watercourses, its close articulation with Catarinense prioritary economy sectors and with the production system which aims for profit and damages the environment. Concerning the school work, we observed that the water topic is discussed in all schools, however it is disconnected from the concrete problems context, which is restricted to the consumption sphere and individual responsibilization.

Keywords: Water Resources; Catarinense Economy; School; Field Education.

Resumen: El artículo presenta resultados de investigación desarrollada en el ámbito del PET/ Educación de Campo/UFSC acerca del problema con respecto a los recursos hídricos en ciudades catarinenses y el trabajo de la escuela con ese tema. Los municipios investigados fueron Urubici, Três Barras y Passos Maia, donde fueron abordados respectivamente el uso de agrotóxicos, la industria del papel y las PHCs. Fueron realizadas entrevistas con estudiantes, docentes y residentes, y observaciones de las escuelas, ríos, fuentes de agua, cultivos e industrias relacionadas. Las conclusiones indican problemas de polución, contaminación y apropiación privada de los cursos de agua, su estrecha relación con los sectores prioritarios de la economía catarinense y con la forma de producción que tiene por objetivo el lucro y degrada el medio ambiente. En cuanto al trabajo escolar, identificamos que el tema agua es abordado en todas las escuelas, pero de manera descontextualizada de los problemas concretos, restringido al ámbito del consumo y de la responsabilización individual.

Palabras clave: Recursos Hídricos. Economía catarinense. Escuela. Educación de Campo. 


\section{Introdução}

O presente artigo sintetiza os estudos e pesquisas realizados pelo Grupo de Educação Tutorial (PET) do Curso de Licenciatura em Educação do Campo da UFSC no período entre 2013 e 2014. ${ }^{1}$ Neste período as atividades do grupo tiveram por centralidade o projeto denominado "Conhecimento popular, científico e a escola", o qual versava sobre como estas formas de conhecimento e instituições abordavam o problema dos recursos hídricos em três municípios catarinenses onde os estudantes ligados ao PET desenvolviam o Tempo Comunidade do Curso de Licenciatura em Educação do Campo da UFSC. Foram desenvolvidas, no período, atividades de ensino, pesquisa e extensão, porém, nesse momento nos concentramos em sintetizar as pesquisas desenvolvidas pelo grupo. Dentre outros, os seguintes objetivos foram elencados: diagnosticar problemas relativos à água em comunidades e escolas onde se desenvolvem o campo de estudos dos bolsistas PET do curso de Educação do Campo e as formas de interpretação/explicação dadas pelas comunidades a partir de seus próprios conhecimentos, ou conhecimentos populares; identificar como as escolas organizam e desenvolvem o currículo, portanto, como abordam os conteúdos relativos à temática dos recursos hídricos, e as questões candentes na realidade local.

A escolha da temática recursos hídricos se enraíza em estudos anteriores do grupo PET, mas também na importância que a questão assume para toda humanidade. Segundo o Relatório da Organização da Nações Unidas, Água e Emprego (ONU, 2016), cerca de 748 milhões de pessoas no mundo não têm acesso a uma fonte segura de água potável e há escassez de água em várias regiões do mundo. A água é um componente essencial das economias nacionais e locais e é essencial para os mais diferentes setores.

As análises realizadas no citado Relatório estimam que metade da força de trabalho mundial está empregada em oito setores dependentes de recursos hídricos e naturais: agricultura, silvicultura, pesca, energia, manufatura com uso intensivo de recursos, reciclagem, construção e transporte. Neste contexto, buscamos investigar o problema dos recursos hídricos em municípios selecionados e o trabalho realizado pelas escolas diante de uma questão vital na história e na atualidade.

Os municípios onde as atividades foram desenvolvidas, todos de pequeno porte e de base agrícola, são o de Urubici, localizado na Serra Catarinense; Três Barras, situado no Planalto Norte e Passos Maia, na região Oeste Catarinense. Em cada um deles definiu-se por estudar problemáticas locais candentes quanto aos recursos hídricos, sendo: a poluição da água por agrotóxicos oriundos
* Doutora em Educação pela UFSC. Professora do Departamento de Estudos Especializados em Educação e do Programa de Pós-Graduação em Educação na UFSC. Faz parte do Núcleo de Pesquisa Transformações no Mundo do Trabalho (TMT).

E-mail: sandradalmagro@yahoo.com.br

** Mestre em Educação pela UFSC. Integrante do Núcleo de Pesquisa Transformações no Mundo do Trabalho (TMT).

E-mail: janaamora@hotmail.com

1 A equipe foi composta por: Tutores: Prof. Sandra Luciana Dalmagro e Prof. Marcos Antonio de Oliveira; Bolsistas: Cristian Gonçalves, Janaina Goulart de Oliveira Queiroz, Raquel Zenirma Martins, Ariane da Silva Paim, Chrislaine Weber, César Diniz Pasqualetti, Evaristo Kluska, Janete Pacheco, Helena Maria Borges, Bruno Lopes Cunha. O artigo sintetiza os estudos e pesquisas desenvolvidos pelo grupo como um todo no citado período. 
da produção de hortaliças em Urubici; a utilização da água pela indústria da madeira em Três Barras; a utilização de cursos de água por parte de empresários para a produção de energia, e as Pequenas Centrais Hidrelétricas - PCHs, em Passos Maia.

Metodologicamente, consideramos que haveria a necessidade de estudar as questões relativas aos recursos hídricos não de forma desvinculada das questões objetivas que definem a vida no campo na atualidade, nem que, sendo forçados a optar por estudos em localidades definidas em grande medida pelo local de realização do Tempo Comunidade dos estudantes, que estas se consubstanciassem em estudos de casos isolados. Ao contrário, referindo-se ao estudo de questões hídricas em campos selecionados num dos mais importantes estados agrícolas do país, o grupo optou por estudos localizados, mas que permitissem uma relação maior com o desenvolvimento rural no Estado, no sentido de aproveitar este momento para que os alunos pudessem fazer as ligações necessárias à formação de um professor em escolas do campo.

Para dar conta dos objetivos propostos, os trabalhos se concretizaram em: a) levantamento bibliográfico sobre questões relativas a recursos hídricos na indústria de madeira/papel/celulose, PCHs e contaminação por agrotóxicos; b) revisão bibliográfica de artigos que versavam sobre educação ambiental na escola; c) levantamento das principais fontes de abastecimento de água em cada uma das três regiões pesquisadas; d) entrevistas com a população sobre os problemas relativos aos recursos hídricos relacionados às três atividades econômicas acima descritas, e) análise dos documentos de planejamento de atividades relativas às disciplinas na área de ciências da natureza em escolas selecionadas e f) observações e entrevistas com professores e alunos destas disciplinas acerca do trabalho sobre o tema recursos hídricos e problemas relativos à sua utilização.

Este artigo apresenta uma síntese destes estudos e pesquisas. O texto inicia localizando a problemática dos recursos hídricos nos três municípios pesquisados, bem como identificando a percepção da população acerca desta situação. Na sequência realizamos alguns apontamentos sobre os estudos realizados nas escolas acerca de como esta aborda os recursos hídricos, para, por fim, expor as considerações finais.

\section{A problemática dos recursos hídricos em Urubici, Três Barras e Passos Maia}

O município de Urubici está situado na serra catarinense a $170 \mathrm{~km}$ da capital Florianópolis. Possui uma área territorial de 1019,1 km² e uma população de 11 mil 
habitantes, sendo que 7 mil vivem na área urbana e 4 mil na área rural. Sua densidade demográfica é de 10,51 hab/ $\mathrm{km}^{2}$ (IBGE-2010). Segundo o IBGE, os setores econômicos do município são os de serviços, turismo, agropecuária (agricultura familiar e patronal), com a produção de hortaliças, maçã, pêssego, ameixa, kiwi, caqui, milho, fumo, entre outras. Os setores de serviços, em particular o turismo de inverno, e a agropecuária são os que mais contribuem com o Produto Interno Bruto - PIB, no entanto, os serviços apresentam um percentual de $60,5 \%$, enquanto a agropecuária representa $23,9 \%$.

O município de Urubici está inserido no Sistema Integrado da Vertente do Interior e do Sistema da Vertente Atlântica na Região do Planalto de Lages - RH $4^{2}$ que está situado sobre a Zona de Recarga Direta do Aquífero Guarani, e é cortado por diversos rios, além de contemplar as nascentes do Rio Canoas e do Rio Lava Tudo. O Rio Canoas corta o município de Urubici e nos últimos anos tem recebido diversos poluentes, contaminantes e agrotóxicos que são provenientes da agricultura na região.

No município há falta de saneamento básico, 61,1\% dos domicílios estão ligados à rede geral de abastecimento de água, os outros domicílios recebem água através da canalização de poços e nascentes. O município de Urubici não apresenta estação de tratamento de efluentes, sendo estes direcionados a fossas mal planejadas ou até, como observado em campo, ter seus efluentes jogados diretamente em diferentes sub-bacias do Rio Canoas.

A agricultura em Urubici faz uso intensivo de agrotóxicos, não destoando do cenário nacional. Os tipos de agrotóxicos mais utilizados são os que pertencem aos grupos químicos dos neonicotinóides, triazinas, benzoiluréia e triazóis. Observou-se que muitos cultivos beiram os rios da região e também não há mata ciliar ${ }^{3}$ nos seus entornos. Segundo os estudantes e professores de uma das escolas pesquisadas em Urubici, a produção da maçã e do tomate são as que fazem o maior uso de agrotóxicos na região. São entre 20 e 40 aplicações ao ano. Os venenos entram em contato com o solo e escorrem para os rios, nascentes e córregos, chegando ao aquífero e dessa maneira comprometem os recursos hídricos da região.

Os moradores afirmam que os rios da região são tanto mais limpos quanto mais próximos de seu nascedouro. No município, as nascentes são normalmente utilizadas para o lazer da população local, pois se encontram em áreas alagadiças dos Campos de Altitude, próximos dos 180om (CURTARELLI; SILVA; FERREIRA, 2010), ausência de ocupação nas suas proximidades e menor poluição.

Durante a pesquisa observou-se que próximo às nascentes existem criações de gado. Conforme exame da
2 O Estado de Santa Catarina para efeito de inter-relação com a gestão dos Recursos Hídricos, estabelece 8 Secretarias de Desenvolvimento Mesorregional e 22 Secretarias Microrregional, conforme Lei Complementar $\mathrm{n}^{0} 284$ de 28/02/05, como indica o estudo do Panorama dos Recursos Hídricos de Santa Catarina. Disponível em: http://www.sirhesc.sds.sc.gov.br/sirhsc/baixararquivo. jsp?id $=167 \&$ NomeArquivo $=$ Panorama $\% 20$ dos\%2o Recursos\%2oHidricos\% 20 de\%2oSanta\%2oCatarina.pdf Acesso em: 10.02.2014.

3 São 14 km de estrada margeando o Rio Canoas. Na paisagem, roças de milho espalhadas por todo nível do antigo patamar do rio, a estrada passando junto ao rio a menos de um metro de mata ciliar. Ainda é possível observar inúmeras araucárias, mas a quantidade de eucaliptos é impressionante. 
vigilância sanitária apresentado pela escola pesquisada, há indícios de fezes de animais na água. Sem filtros de captação, o consumo de água dessas nascentes é realizado por boa parte da população e também pela escola. Sendo assim, identificou-se que quase a maioria da população desconhece essa realidade e acaba por consumir essa água. Compreende-se que a utilização dos rios pela população para fins recreativos também está comprometida, sendo que não se pode mais tomar banho em suas águas tranquilamente, sabendo que há uma possível contaminação por substâncias químicas. Houve inclusive relatos de alunos sobre coceiras após tomarem banho de rio.

A forma como é desenvolvido o trabalho agropecuário entra em contradição com a imagem que o município vende como lugar de belezas naturais. Urubici e região atraem turistas pelas belezas da serra e o clima frio; parte importante da economia do município advém do turismo, em particular no inverno. Enquanto as paisagens bonitas e o clima frio são vendidos aos turistas, a agricultura convencional destrói parte desta natureza e suas belezas, retirando dos turistas e sobretudo da população local algumas possibilidades de uso do ambiente. A natureza que se vende por sua beleza e clima é a mesma que se destrói por meio do desmatamento e agrotóxicos.

Já a região do Planalto Norte Catarinense, onde fica situado o município de Três Barras, compreende uma área de aproximadamente $10.466,70 \mathrm{Km}^{2}$ e uma população total de 335.154 habitantes, sendo que 89.122 habitantes vivem na área rural. A região possui grande plantação de árvores exóticas, ou seja, pinus (Pinus elliottii) e eucalipto. Segundo o IBGE (2010), "produtos da silvicultura - madeira em tora para papel e celulose", chegou a atingir a produção de $2.168 .820 \mathrm{~m}^{3}$ na região. O município de Três Barras ocupa uma área de $438.066 \mathrm{~km}^{2}$. A população é de 18.131 habitantes e uma densidade demográfica de 41,39 hab./km (IBGE, 2010).

Ainda segundo o IBGE (2010), a economia do município envolve a agropecuária e a agricultura familiar, através da produção de arroz, aveia, batata inglesa, cebola, feijão, fumo, milho, trigo, fumo, mandioca, leite, frutas, mel, soja, pinus e eucaliptos. As indústrias que se destacam no município e região são as de celulose e papel, madeireira, química, ração, além dos setores de comércio e serviços.

O município está inserido no Sistema Integrado da Vertente do Interior e do Sistema da Vertente Atlântica na Região de Canoinhas-RH 5, região hidrográfica do Paraná, a qual abrange parte da região sudeste. Segundo a Agência Nacional das Águas (ANA, 2013) é a região com maior demanda por recursos hídricos do país, com $32,1 \%$ da população nacional e que apresenta o maior desenvolvimento 
econômico do país. Os rios Canoinhas, Argentina e Negro compõem esse sistema, sendo este último o que abastece a população do município. A área urbana recebe água tratada, sendo que na área rural é utilizada água de poço.

As indústrias de celulose e papel são as atividades que mais consomem água e que acabam por gerar uma enorme quantidade de efluentes. Nesse sentido, a vigilância sanitária aponta para vestígios de metais nos rios da região, mas não em quantidades suficientes para prejudicar a saúde do consumidor. O município de Três Barras também não possui tratamento de lixo e esgoto, sendo utilizadas fossas sépticas, mas cerca de um terço da população direciona o esgoto e demais resíduos urbanos para os rios da região (IBGE, 2010). O lixo urbano é transportado para a cidade vizinha de Mafra.

Os relatos da população indicam que a produção agrícola tem utilizado grande quantidade de agrotóxicos e adubos químicos entre eles: Glifosato, Sanson, Fuseflex e Podion. No município de Três Barras os problemas que foram se apresentando na pesquisa, e confirmados por alguns moradores, envolvem o uso de agrotóxicos e os dejetos das indústrias de celulose e papel. Buscando saber como a população percebe o problema dos recursos hídricos do município, se questionou: "Pode-se considerar limpa à água dos rios hoje em dia? Se não, que tipo de poluição os rios sofrem?”.

Não, antigamente nós tomávamos água direto do rio, hoje não dá para confiar nem na água da Samasa que é captada do rio e tratada (Entrevistado 1).

Os rios sofrem a poluição da fábrica e também da própria população que solta o seu esgoto direto nos rios, também jogam lixo dentro do rio. É um problema muito grande até porque a prefeitura não fornece tratamento de esgoto, não existe uma política de saneamento básico (Entrevistado 2).

Nas entrevistas realizadas com a comunidade, tanto na área rural como na área urbana, os moradores mais antigos da região expressaram falas muito próximas, indicando que as empresas destruíram as nascentes, a flora e a fauna, que o pinus "seca" o terreno, que há poluição dos rios, mas ao mesmo tempo afirmam que as empresas de celulose trouxeram empregos. Nesse sentido, percebe-se que a população, principalmente os habitantes mais antigos, percebem que a industrialização, o reflorestamento de pinus e o uso de agrotóxicos contribuíram para a poluição e destruição dos recursos hídricos do município, mas ao mesmo tempo são levados a aceitar ou mesmo suportar tal 
condição, pois lhes falta uma visão crítica global quanto ao modo de produção que leva a estes problemas, o mesmo que os leva a se tornarem dependentes das vagas de emprego. Assim, os entrevistados oscilam entre a crítica à indústria que polui e contamina e o enaltecimento da mesma pelas vagas de trabalho.

Schaefer e Jantsch (1995) apontam que o saber popular é ambíguo, oscilando entre perspectivas e fontes opostas sem perceber a contradição aí contida, sem conseguir avançar para um pensamento complexo e uma visão de totalidade: "[...] nos parece correto concluir é que as ambiguidades presentes no popular são resultantes das contradições reais existentes e persistentes na sociedade. A contradição, como tal, não contém ambiguidade; a ambiguidade, para ser tal, não contém contrariedade" (1995, p. 32-33).

Na mesorregião do Oeste Catarinense, Microrregião de Xanxerê, está localizado o município de Passos Maia. O município está a $512 \mathrm{~km}$ distantes da capital, e possui uma população de 4.425 pessoas, sendo que $75,2 \%$ são residentes na área rural e 24,8\% na área urbana. Passos Maia integra-se à Unidade de Conservação de proteção integral no Parque Nacional das Araucárias, juntamente com 14 Assentamentos da Reforma Agrária. Os assentamentos na região se encontram na área de amortecimento do parque. Os lotes nos assentamentos têm entre 15 a 20 hectares e estão baseados na produção de subsistência, sobretudo leite, grãos, fruticultura, mel e carvão.

O espaço territorial de Passos Maia é de 614 km², porém, apenas $150 \mathrm{~km}^{2}$ estão destinados à agricultura, 464 $\mathrm{km}^{2}$ são áreas de latifúndios com exploração extensiva do gado de corte, erva mate, reflorestamento, extração da madeira para beneficiamento, empresas agroflorestais, grandes fazendas com base no monocultivo e para agroexportação. A economia do município conta ainda com o setor moveleiro, comércio varejista e atacadista, transporte de carga e o setor energético, este último em crescimento.

O município é cortado pelos rios Chapecó e Chapecozinho e estes estão ligados ao Sistema Integrado da Vertente do Interior e do Sistema da Vertente Atlântica na Região Hidrográfica - RH2 - Meio Oeste - que compreende as duas Bacias: a do rio Chapecó e a rio Irani, que pertencem à Bacia do Uruguai. A RH2 é a única bacia hidrográfica do estado catarinense que até o momento da pesquisa não possuía Comitê de Bacia Hidrográfica ${ }^{4}$ oficialmente estabelecido.

Em Passos Maia, somente 36,1\% dos moradores tem acesso à rede de água geral com canalização, sendo 50,2\% com esgotamento sanitário adequado. O solo e os recursos hídricos vêm sendo poluídos por falta de saneamento básico e por dejetos industriais, principalmente celulose e suínos e o uso de agrotóxicos (IBGE, 2010).
4 Comitê de Bacia Hidrográfica é um órgão colegiado da gestão de recursos hídricos, com atribuições de caráter normativo, consultivo e deliberativo e integra o Sistema Estadual de Gerenciamento de Recursos Hídricos. Os Comitês devem integrar as ações de todos os Governos, seja no âmbito dos Municípios, do Estado ou da União; propiciar o respeito aos diversos ecossistemas naturais; promover a conservação e recuperação dos corpos d'água e garantir a utilização racional e sustentável dos recursos hídricos. Disponível em: http:// www.semarh.se.gov.br/comitesbacias/ modules/tinydo/index.php?id=23. Acesso em: 27.jan.2014. 
Nos últimos anos, o município vem recebendo um grande número de Pequenas Centrais Hidrelétricas PCHs, devido à região ter rios com grande volume de água. São grandes grupos de investidores financeiros internacionais do setor energético que se instalam na região para produção e venda de energia, entre eles, a Holding ATLAN$\mathrm{TIC}^{5}$ de energias diferenciadas. Segundo dados do Relatório Santa Catarina em Números (SEBRAE, 2013), a atividade econômica de geração, transmissão e distribuição de energia elétrica vem gerando lucro para o município e está quase ultrapassando o setor madeireiro. Em nossas observações durantes as pesquisas realizadas no município, foi constatado um número total de nove PCHs na região, mas esse número deve aumentar em função da grande demanda de licitações na região.

Segundo relatos de moradores do município, após as implantações das PCHs, ocorreram transformações no meio ambiente da região, principalmente no clima, afetando a agricultura, porém não existiam estudos específicos a respeito.

Em Passos Maia os rios também são utilizados pela população para lazer, pescarias, acampamentos e para o uso dos animais. A implantação das PCHs na região passa quase despercebida pela população do município e isto envolve a ausência da participação popular nos processos que decidem acerca da instalação destas unidades. Os depoimentos abaixo evidenciam isto.

Já ouvi falar, mas eu não conheço esse negócio. Ah! Aquelas barragens acho que deve ter uma 3 ou 4. Tem no Chapecozão, tem 2 ou 3 lá, uma aqui perto e uma mais para baixo. Sobre as outras, não sei... (Entrevistado 10).

Pelo que a gente tá sabendo, é por causa da mata, porque também foi destruído um pouco da mata, eu acho que é isso eu não sei também, eu não sei na verdade... (Entrevistado 20).

Olha, eu acho que talvez isso daí venha trazer algum benefício, por exemplo, assim para o município, que vem para Prefeitura. É para energia (Entrevistado 40)

A população de Passos Maia tem vaga noção da existência das PCHs na região, porém não conseguem identificar quantas e quais são elas e o porquê estão instaladas na região. Muitos sabem que as mesmas servem para gerar energia, mas não identificam a geração de capital a partir da energia e a apropriação de forma privada dos bens naturais e sociais. Envolta na pseudoconcreticidade (KOSIK, 2002) a população desconhece os interesses dos grandes
5 Disponível em: http://atlanticenergias.com.br/. Acesso e: 12.abr.2014. 
grupos econômicos nacionais e internacionais que atuam na região, os quais privatizam a água e a terra, retirando lucro pelo uso dos bens naturais e que deveriam estar a serviço de todos. A maioria da população se encontra em condições de pobreza, desconhece o que se passa na região e não participa das decisões do município no que se refere à instalação das Pequenas Centrais Hidrelétricas ou quanto aos recursos financeiros repassados por estas ao município. Também identificamos que a falta de energia no município é recorrente, o que pode estar ligado às instalações precárias e ultrapassadas do sistema de energia do município. Contraditoriamente, o mesmo local que vem produzindo energia em abundância, sofre pela falta do recurso que produz.

Nesse sentido, vê-se a importância que o tema água possui. Nos três municípios pesquisados identificou-se a apropriação privada deste bem público, seja para o cultivo agrícola, industrial ou energético. Também em comum é a degradação ambiental, em particular a poluição e a contaminação, e seu impacto na vida população local. Nos três municípios também observamos que a população reconhece problemas decorrentes do uso inadequado da água, mas não alcança uma visão mais profunda e articulada quanto às suas causas, tendendo a uma percepção imediata ou mesmo ambígua. No texto que segue versamos sobre o trabalho das escolas com a temática dos recursos hídricos.

\section{O trabalho das escolas sobre os recursos hídricos}

A pesquisa nas escolas selecionadas procurou identificar se e como os recursos hídricos eram abordados na escola, quais materiais foram utilizados, bem como o conhecimento dos mesmos, observação das atividades quando este conteúdo foi enfocado, entrevistas com estudantes, professores e direções, assim como observações no conjunto da escola e análise de seus documentos principais no intuito de compreender a proposta pedagógica efetivada.

Observamos que o assunto é abordado basicamente em sala de aula, e particularmente na disciplina de geografia. São praticamente inexistentes as visitas de estudos, pesquisas e seminários. O material utilizado foi, majoritariamente, livros didáticos. Descrevemos e analisamos abaixo, sucintamente, a situação encontrada em cada local.

No município de Urubici duas escolas foram pesquisadas; na área rural, uma escola municipal que atende o Ensino Fundamental e na área urbana, uma escola estadual que atende o Ensino Fundamental e o Ensino Médio. $\mathrm{Na}$ escola localizada no campo o estudo sobre recursos hídricos durante o período pesquisado fora pautado em 
questões como o desperdício de água no dia-a-dia, a utilização da água para lazer, higiene pessoal e consumo em geral. Na escola urbana o tema da água emergiu a partir do Projeto Nascentes do Futuro, promovido pela Associação dos Municípios da Região Serrana. Este projeto tinha por objetivo cuidar das nascentes e das fontes de captação, garantindo água a o consumo humano das atuais e futuras gerações. Soube-se ainda que no ano de 2011 em Urubici, foi realizado o projeto microbacias da EPAGRI, juntamente com o Corpo de Bombeiros do município e com os estudantes, através de coletas de lixo no Rio Canoas, a fim de desenvolver a percepção de não jogar mais lixo nos rios da região, porém, no período da pesquisa o trabalho sobre recursos hídricos ocorreu exclusivamente dentro da escola.

As duas escolas pesquisadas, ao abordarem o tema água o fazem sobretudo com relação ao consumo doméstico, desconsiderando a participação relativamente pequena deste no uso total da água, cuja maior parte é destinada à agricultura irrigada e à indústria. Deste modo, o estudo sobre a água na escola ocorre de maneira superficial, pois não abrange a problemática ambiental de forma mais ampla, considerando o modelo produtivo atual e não apenas o consumo. Também não indicam para seus estudantes os impactos que as grandes indústrias e a agricultura de monocultivo vem produzindo no meio ambiente, ou seja, através da contaminação do solo, da água, pelo uso exaustivo de agrotóxicos, produtos químicos e pelo grande consumo e desperdício de água potável. Desconsidera-se assim a experiência dos próprios estudantes, os quais nos confirmam que os rios e arroios que eles utilizam para banho vem se reduzindo, decorrente da poluição dos agrotóxicos. Segundo Silva e Souza (2009), é essencial considerar a realidade dos atores sociais quanto ao contexto da Educação Ambiental, possibilitando uma visão crítica acerca do meio ambiente, dentro de um caráter histórico e social, desvinculando-se de uma visão predominantemente reducionista.

No município de Três Barras a pesquisa ocorreu em uma escola estadual que atende o Ensino Fundamental, Médio e Pós Médio. Observou-se que os temas recursos hídricos e saneamento básico vêm sendo abordados a partir dos livros didáticos, sem que outras fontes de informação fossem acionadas. A abordagem predominante responsabilizava os indivíduos, de forma genérica, sobre os problemas ambientais e não estabelecia relação destes problemas com o modo de produção vigente, ou seja, atém-se ao consumo individualizado e não à produção industrial ou agroindustrial em larga escala. Também se observou que poucas são as relações estabelecidas entre o conteúdo dos livros e a realidade em que vivem os estudantes, o que compromete a aprendizagem e mesmo o significado da escola para os 
estudantes. O movimento entre o local e o global, entre o concreto e o abstrato são essenciais no processo de ensino e aprendizagem, sobretudo na Educação Fundamental, quanto os conceitos abstratos ainda estão em formação (VIGOTSKI, 2000).

A fala dos jovens do ensino médio da escola revela que após o estudo do tema recursos hídricos eles não ultrapassaram o senso comum sobre o assunto. Quando perguntados: "Você considera estes rios limpos ou poluídos? O que você aprendeu na escola sobre os rios?”, as respostas foram frágeis.

Poluídos, jogam sujeira nele (Estudante 1).

Que sempre devemos ser conscientes dos nossos atos, para não poluir os rios (Estudante 2).

Devemos sempre beber água bem tratada e não poluir os rios (Estudante 3).

A percepção dos estudantes de Ensino Médio com relação aos recursos hídricos e os problemas decorrentes de sua utilização, poluição e contaminação pela indústria papeleira da região, é muito frágil. Expressam o discurso corrente - não poluir - e não uma análise do problema porque estão sendo poluídos e como, o que seria de esperar nesta etapa de ensino, quanto mais na sequência do assunto ter sido abordado na escola. Os recursos hídricos foram estudados, durante o período da pesquisa, sobretudo através do livro didático, mas sem muito aprofundamento e sem que o docente estabelecesse articulação com a realidade dos estudantes. Desta forma a escola, neste caso específico, parece não contribuir para superar a visão fragmentada do real, levando o indivíduo a agir num mesmo quadro referencial cognitivo, não conseguindo dar um salto em suas concepções e práticas, o que seria esperado após o estudo deste conteúdo, denotando que não houve uma aprendizagem significativa ou efetiva.

Segundo Schaefer e Jantsch (1995), o saber científico supõe a capacidade de saber inter-relacionar partes aparentemente dispersas, contribuindo para uma análise estruturante do problema. O que a pesquisa deste conteúdo na escola constatou é que esta não alcançou a compreensão teórica do problema hídrico, portanto uma abordagem científica. O trabalho realizado não ultrapassou o discurso corrente acerca da não poluição, não contribuiu para uma análise das causas para além das aparências. Neste sentido, mantém a percepção dos estudantes quanto a questão hídrica num universo imediatista, acrítico e fragmentado. 
No município de Passos Maia, foi pesquisada uma escola que atende a Educação Infantil, o Ensino Fundamental, a Educação de Jovens e Adultos e o Ensino Médio. O tema dos recursos hídricos vem sendo tratado apenas pelo livro didático (Apostila Positivo) ${ }^{6}$ em sala de aula e poucos são os estudos e as discussões na escola a respeito.

Somente três estudantes entre dez entrevistados já ouviram falar e conseguem identificar que as barragens no município estão associadas à questão energética. A abordagem do tema água ocorreu em algumas disciplinas, ainda que um tanto superficial, mas considera-se que já houve aprendizados, pois alguns estudantes compreendem a importância da preservação dos rios, da não poluição, do problema dos agrotóxicos, bem como a importância das PCHs na produção de energia. Mas existem limites quanto aos temas e esses precisam ser superados a partir de um olhar crítico, pois muitos estudantes associam a limpeza dos rios a partir do que enxergam imediatamente, ou seja, se o rio possui lixo, mas pouco compreendem a contaminação, que nem sempre é visível a olhos nus. A abordagem da questão ambiental e hídrica é descontextualizada, frágil conceitualmente, acrítica e desconsidera o problema hidrográfico local.

Segundo Silva e Souza (2009), a crise ambiental que vivemos atualmente decorre do agravamento da lógica da apropriação privada dos recursos humanos e naturais, que na ordem econômica competitiva, levam ao uso abusivo. Deste modo, importa questionar e discutir a posição do ser humano e da sociedade, seus modos distintos e interesses ao se relacionar com o ambiente e com os outros humanos.

\section{Considerações finais}

Como indicamos, os estudos realizados no PET Licenciatura em Educação do Campo UFSC apontavam para a necessidade de estudar as questões relativas aos recursos hídricos não de forma desvinculada das questões objetivas que definem a vida no campo na atualidade. Por conta disto, o estudo da questão hídrica buscou: a) em Urubici, relacioná-la à forma de aproveitamento do meio-ambiente para a indústria do turismo, principalmente aquele relacionado ao clima mais frio do Brasil, típico daquela região; b) em Três Barras relacioná-la ao modelo de desenvolvimento da região e, nesta, principalmente à evolução da exploração da madeira, um dos principais produtos da exploração econômica da região e a grande propulsora da industrialização local, tanto no setor da madeira propriamente dita, quando do setor de papel e celulose; c) em Passos Maia, relacioná-la ao aparecimento/incremento de um novo tipo de exploração capitalista na agricultura catarinense, agora utilizando o meio rural como ofertante de
6 Compreendemos que o sistema de apostilamento é uma forma de privatização e mercantilização do ensino, tende às perspectivas tecnicistas em educação e limita o desenvolvimento dos estudantes e o trabalho do professor. Sobre isto ver Frutuoso (2014) e para uma crítica mais ampla dos processos de privatização em curso no Brasil ver Freitas (2009). 
energia para outros setores de atividade econômica e ou moradias urbanas e mesmo no campo, na transformação da gravidade em mais-valia, via exploração de cursos e quedas de água para a produção de energia elétrica através das PCHs.

Estas questões relacionam-se entre si no desenvolvimento do espaço rural do Estado catarinense, haja vista, como ademais em praticamente todas as regiões rurais do Brasil, o avanço da produção capitalista em larga escala que tira margem de manobra da pequena exploração agrícola, retira pessoas do campo e as concentra em médios e pequenos municípios, restando à região de Urubici especializar-se no turismo, explorando seu principal atrativo, o clima frio; à Região de Três Barras/Canoinhas especializar-se na exploração da indústria da madeira, à Passos Maia (região fria, úmida e de topografia bastante irregular) especializar-se na exploração privada de mais um recurso natural (água).

No que se refere ao uso dos recursos hídricos por parte da indústria madeira/papel/celulose no Planalto Norte catarinense, esta se utiliza de quantidade expressiva de volumes de água para seus processos produtivos, bem como explora e ocupa o solo de boa parte dos municípios de sua área de atuação com o plantio de espécies florestais, principalmente o pinus. Quanto ao município de Passos Maia, grandes empreendimentos rurais se fazem presentes na exploração de PCHs, capitaneados por capitais que se relacionam com proprietários fundiários, exploração da madeira e a indústria revendedora de máquinas e equipamentos industriais. Neste processo, a população do município não participa como proprietária/sócia dos benefícios do negócio, ficando unicamente com promessas de emprego e o enfrentamento aos problemas oriundos das mudanças microclimáticas, para além das perdas de terra por desapropriação a custos por elas considerados abaixo do preço de mercado das terras. Finalmente, o estudo também verificou a existência de contaminação das águas por conta dos agrotóxicos utilizados no cultivo das hortaliças e frutíferas em Urubici, com prejuízos às fontes de água para uso das escolas, população e turistas. A natureza que se destrói pela agricultura de tipo capitalista é a mesma que se vende na indústria do turismo.

No tocante às formas com que as populações destas localidades explicam estas questões, verificou-se que parte identifica ou sente os problemas decorrentes das formas destrutivas de uso dos recursos hídricos, mas não faz uma ligação entre o que vê/sente e uma explicação de suas causas e contexto para além do imediato, possui dificuldade em perceber os determinantes mais profundos dos problemas. Assim, tende a assumir a forma ambígua ao pensar a 
relação entre desenvolvimento econômico e meio ambiente do que a pensar por contradições.

Com base em Andery et al (2006), compreendemos que as formas de conhecer são históricas; o que e como a humanidade conhece tem relação com o conjunto da vida, em particular as relações de trabalho de cada tempo histórico, de cada sociedade. A compreensão do real e as formas de o acessar são modificadas com as mudanças sociais de igual modo, o que e como se ensina também é produto histórico.

A relação entre o conhecimento popular e o conhecimento científico é controversa; no campo educacional em que nos encontramos, tampouco é consensual. Assumimos neste artigo a compreensão de que a ciência é a forma mais desenvolvida de conhecimento, no sentido de que possui um método rigoroso, exige explicação/ demonstração, busca as causas dos fenômenos explicando as relações entre essência e aparência, refuta os dogmas e é sujeita à crítica (SEVERINO, 2007, MINAYO, 2007, ANDERY, 2006). Mas isto não significa afirmar que a ciência é isenta de limitações. Lukács (2012), por exemplo, assinala que sob o capitalismo a ciência é cada vez mais manipulatória; adaptada aos interesses burgueses deixa de ter compromisso com a verdade. A ciência, assim como as demais formas de conhecer o mundo, se desenvolvem considerando as condições do mundo em que se encontram.

O conhecimento científico ainda se encontra pouco acessível à população, mesmo a que frequenta a escola, como identificamos. A rigor, a população - e os estudantes em particular - quase sempre acessam fragmentos do conhecimento científico (MANACORDA, 2000), e raramente chegam à efetiva apropriação de conceitos e a teorias explicativas. Estes pressupõem a articulação de um conjunto de conhecimentos coerentemente organizados e interrelacionados acerca de situações complexas e que exigem alto grau de abstração.

O chamado conhecimento popular é um termo amplo e guarda imprecisão. Neste artigo nos embasamos em Schaefer e Jantsch (1995) os quais consideram o conhecimento popular como uma forma de conhecer assistemática e empiricista, pautado na relação direta e imediata com a realidade, sem a mediação da teoria. Isto não significa dizer que a forma popular de conhecer e compreender o mundo não tenha depurado verdades, o que seria um equívoco considerando que a humanidade por milhares de anos, e ainda hoje, produziu sua existência - e inclusive a ciência tendo por base esta forma de apreensão do mundo.

No que se refere à forma como as escolas trabalham as questões relativas aos recursos hídricos, verificou-se a relação direta do ensinado com o que se apresenta nos 
livros didáticos. Como estes são concebidos em esferas e espaços outros que não o local, trazem uma necessária bagagem de conceitos científicos, mas não os contextualizam para as situações vividas. No estudo, verificou-se que as escolas também não o fazem, o que efetivamente contribui para a defasagem da população em relação ao entendimento de suas situações concretas.

Esta questão é cara para nós, ou seja, a definição de uma escola que não se distancie do universal, mas que use o conhecimento clássico para entender a realidade dos estudantes. Neste aspecto se destacou a forma como a questão ambiental vem sendo abordada, não apenas nas escolas mas também nestas, em geral desconsiderando o modo de produção como poluidor e degradador do ambiente, ao passo em que se responsabiliza cada indivíduo pelo problema ambiental. Portanto, investigar a dinâmica econômica das regiões em articulação com a produção global, foi esclarecedor no sentido de identificar as causas fundamentais dos problemas hídricos, para além do discurso do desperdício ou da falta de consciência ambiental.

A conclusão obrigatória é que há ainda muito que se fazer, no campo da organização da escola, para um efetivo estabelecimento de métodos de ensino que fazem a concatenação entre conhecimento científico e popular. No mínimo, que ultrapasse o discurso de que esta articulação é necessária. Nos encontramos ainda diante de uma escola que fica no campo do formalismo pedagógico, mais afeito ao trabalho com grandes temas, estes, porém distante da realidade concreta.

\section{Referências}

ANA, Agência Nacional das Águas. Disponível em: http:// www2.ana.gov.br/Paginas/portais/bacias/parana.aspx. Acesso em: 11.nov.2013.

ANDERY, Maria Amália P. B. et al. Para compreender a ciência: uma perspectiva histórica, 15. ed. Rio de Janeiro: Garamond, 2006.

ATLANTIC ENERGIAS RENOVÁVEIS S.A Disponível em: http://www.atlanticenergias.com.br/. Acesso em: 12.abr.2014.

CURTARELLI, Marcelo P. SILVA, Daniel J. FERREIRA, Celso M. Estudo do balanço hídrico na Bacia do rio Canoas em Urubici, SC, Brasil: subsídio a proteção da zona de recarga direta do Sistema Aquífero Guarani. Disponível em: <www.ambi-agua.net/seer/index.php/ambi-agua/article/download/.../76> Acesso em:o6.fev.2014. 
ESTUDO DO PANORAMA DOS RECURSOS HÍDRICOS DE SANTA CATARINA. Disponível em: http:// www.sirhesc.sds.sc.gov.br/sirhsc/baixararquivo. jsp?id=167\&NomeArquivo=Panorama\%20dos\%20Recursos\%20Hidricos\%20de\%20Santa\%20Catarina.pdf Acesso em: 10.fev.2014.

FREITAS, Luis. C. de Os empresários e a política educacional: como o proclamado direito à educação de qualidade é negado na prática pelos reformadores empresariais. In: Germinal: Marxismo e Educação em Debate, Salvador, v. 6, n. 1, p. 48-59, jun. 2014.

FRUTUOSO, Aldani S. de A. O sistema apostilado na rede municipal de ensino de Florianópolis: "caminho" para medidas privatistas e desvalorização da educação. Dissertação (Mestrado em Educação). Programa de Pós Graduação em Educação: UFSC, 2014.

IBGE. Censo Demográfico 2010. Disponível em: http://www.censo2010.ibge.gov.br/sinopse/index. php? $\mathrm{uf}=42 \&$ dados $=0$. Acesso em: 04.fev.2014.

IBGE. IBGE Cidades. Disponível em: »http://cidades. ibge.gov.br/xtras/temas.php?lang=\&codmun=421360\&id tema $=102 \&$ search $=$ santa-catarina $\mid$ porto-uniao $\mid$ extracao-vegetal-e-silvicultura-2011« Acesso em: 23.nov.2013.

KOSIK, Karel. Dialética do concreto. 7. ed. Rio de Janeiro: Paz e Terra, 2002.

LUKÁCS, Gyorgy. Neopositivismo. In: Para uma ontologia do ser social. São Paulo: Boitempo, 2012.

MANACORDA, Mario M. História da Educação: da antiguidade aos nossos dias. 8. ed. São Paulo: Cortez, 2000.

MINAYO, Maria C. (org). Pesquisa social: teoria, método e criatividade, 25. ed. Petrópolis: Vozes, 2007.

ONU.RelatórioÁguae Emprego. Disponível em:http:// unesdoc.unesco.org/images/o024/002441/244103s.pdf. Acesso em: 21.out.2016.

SCHAEFER, Sérgio; JANTSCH, Ari Paulo. Conhecimento Popular, Rio de Janeiro: Vozes, 1995.

SEBRAE. Santa Catarina em Números. Disponível em: http://www.sebrae.com.br/uf/santa-catarina/acesse/ estudos-e-pesquisas/sc-em-numeros/municipais/relatorios-municipais/html-relatorios-municipais/relatorio-municipal-passos-maia.pdf. Acesso em: 27.jan.2014. 
SECRETÁRIA DO ESTADO DE MEIO AMBIENTE E RECURSOS HIDRICOS, Disponível em: http://www.semarh.sc.gov.br/comitesbacias/modules/tinydo/index. php?id=23. Acesso em: 27.jan.2014.

SEVERINO, Antônio J. Metodologia do trabalho científico, 23. ed. São Paulo: Cortez, 2007.

SILVA, Gabriela Ventura; SOUZA, Isabela Gabriel Félix, Contribuições para a Promoção de uma Educação Ambiental Crítica: as percepções de estudantes do ensino médio sobre a crise ambiental. VII ENPEC, Florianópolis, 2009.

VIGOTSKI, Lev S. A construção do pensamento e da linguagem, 2. ed. São Paulo: Martins Fontes, 2009.

Recebido em: 12-10-2019 Aprovado em: 29-04-2020 Publicado em: 22-05-2020 